\title{
GASTOS TRIBUTÁRIOS E RECURSOS ORÇAMENTÁRIOS NAS POLITICAS CULTURAIS
}

\author{
Eduardo Gomor dos Santos \\ Ministério do Desenvolvimento Social e Combate à Fome (MDS) \\ Carla Beatriz de Paulo \\ Casa Civil da Presidência da República
}

\section{GASTOS TRIBUTÁRIOS E RECURSOS ORÇAMENTÁRIOS NAS POLÍTICAS CULTURAIS}

Resumo: Este trabalho analisa a disponibilização de recursos públicos para as políticas culturais no Brasil. 0 estudo parte de uma relação intrínseca entre cultura e política, entre formas de ver, viver e pensar o mundo e suas consequências políticas, identificando uma relação umbilical entre cultura e hegemonia em sociedades de classes. Analisa as leis de incentivo via renúncia fiscal, notadamente o mecenato, que apresentam valores anuais próximos ao do orçamento do próprio Ministério da Cultura; e o Programa Cultura Viva, que significou uma importante mudança na lógica da intervenção estatal na temática cultural. Conclui que as leis de incentivo perdem em controle democrático e reproduzem desigualdades regionais, com alta concentração de recursos em São Paulo e no Rio de Janeiro, servindo como instrumento de marketing para grandes corporações. O Programa Cultura Viva, por outro lado, apresenta distribuição mais equitativa de recursos, mas ainda tem orçamento irrisório comparado aos valores captados pelas leis de incentivo.

Palavras-chave: Políticas culturais, hegemonia, fundo público, leis de incentivo, Programa Cultura Viva.

\section{TAX EXPENDITURES AND BUDGETARY RESOURCES ON CULTURAL POLICIES}

Abstract: This paper analyses the availability of public resources for Brazilian cultural policies. The study comes from an intrinsic relation between culture and politics, between ways of seeing, living and thinking the world and its political consequences, identifying the umbilical link between culture and hegemony in classes societies. Analyses laws based on tax waiver, specifically patronage, which presented annual values similar to the Ministry of Culture budget itself; and Living Culture Program, which represented a significant change in State intervention in cultural themes. It concludes that incentive laws mean losses in democratic control and also reproduce regional inequalities, with higher resources concentration in São Paulo and Rio de Janeiro, acting as marketing tool for large corporations. Living Culture Program, on the other hand, presents a more equality public resources distribution, but is still contemplated with a derisive budget compared to incentive laws.

Keywords: Cultural Policies, hegemony, public resources, incentive laws, Living Culture Program. 


\section{INTRODUÇÃO}

Este trabalho procura discutir as políticas culturais no Brasil a partir da década de 1990, mais especificamente acerca dos recursos disponibilizados para a temática da cultura, com foco nas características do financiamento, principalmente nas relações entre gastos tributários $^{1}$, representados pelas leis de incentivo baseadas na renúncia fiscal, e recursos orçamentários, identificados pelo Programa Cultura Viva. Com o avanço do neoliberalismo na década de 1990, a temática da cultura passa cada vez mais a ser vista como um bom negócio, e as políticas culturais também passam a refletir esse ideário, promovendo uma forte imbricação entre cultura e capitalismo, principalmente com a intensificação da utilização das leis de incentivo via renúncia fiscal pelas grandes corporações.

A partir do aprofundamento da mudança do paradigma da acumulação fordista para a flexível, com suas implicações sobre a produção e principalmente sobre o consumo com relevante destaque para o papel da cultura e a determinação do valor imaterial das empresas e de suas mercadorias - as leis de incentivo teriam se tornado uma excelente forma de promover a marca das corporações em dimensões transcendentais (branding, na linguagem corrente de negócios), a partir de manifestações culturais por elas determinadas.

As leis de incentivo via renúncia fiscal disponibilizam recursos extraorçamentários em valores muito próximos ao próprio orçamento do Ministério da Cultura, impossibilitando, por exemplo, o controle democrático exercido pelo Legislativo sobre a destinação dos recursos envolvidos. Em 2012, por exemplo, foi captado cerca de R\$1,3 bilhão (BRASIL, 2004), contra um orçamento executado pelo Ministério da Cultura de R\$1,964 bilhão (BRASIL, 2014). Como o orçamento do Ministério abarca não somente o financiamento cultural, mas também despesas correntes como folha de pagamento, materiais e infraestrutura ${ }^{2}$, pouco resta para a área finalística, indicando que 0 principal mecanismo de financiamento na área cultural está concentrado no investimento público, mas com alocação ao sabor da racionalidade do mercado, impossibilitando o controle democrático (que já é baixo mesmo para os recursos orçamentários) e cuja lógica reflete a concentração de recursos em alguns poucos estados.

Assim, as leis de incentivo via renúncia fiscal têm exercido um papel fundamental na conformação de hegemonias na contemporaneidade, na medida em que determinam as formas de alocação dos recursos públicos, e dessa forma possibilitam que os sujeitos possam participar ou não de determinadas formas da riqueza imaterial da sociedade. Ao lado das políticas educacionais, exercem um papel fundamental na difusão e consolidação de valores, de modos de ver e viver o mundo, atuando ativamente na ação e reflexão dos sujeitos sobre o que são e o que podem vir a ser, marcando intrinsecamente as relações entre o passado, o presente e 0 futuro. Nesse sentido, suportam hegemonias que mantêm os grupos dominantes e o status quo vigente.

As políticas culturais desempenham um papel fundamental na promoção da equidade de acesso tanto à produção e difusão das manifestações culturais quanto sua fruição por toda a sociedade. Atualmente, a extrema concentração dos meios de comunicação, aliada à propriedade cruzada de diferentes mídias pelos mesmos grandes grupos de comunicação impossibilitam a identificação de modos de vida que sejam diversos da hegemonia vigente. Não faz nenhum sentido que as ideias e valores do eixo Rio-São Paulo sejam exaustivamente veiculados como os únicos civilizados a todo o restante do país. Assim, as políticas culturais podem possibilitar, de fato, que diferentes maneiras de ver e viver o mundo possam alcançar a esfera pública e promover 0 embate entre estas e as culturas hegemônicas.

$\mathrm{Na}$ primeira parte do texto é feita uma breve referência às ideias de Gramsci sobre cultura e hegemonia, suportando teoricamente esta pesquisa; na segunda parte, é identificada a relevância das políticas culturais na contemporaneidade, especificamente a partir do modo de acumulação flexível; na terceira parte, são identificados o mecanismo e os 
principais dados sobre as leis de incentivo com base na renúncia fiscal; na última parte, são identificadas as características do Programa Cultura Viva, como contraponto às leis de incentivo. Os dados que suportam as análises têm origem no Ministério da Cultura, em avaliações e pesquisas do Instituto de Pesquisa Econômica Aplicada (IPEA), além de dados extraídos do Sistema de Apoio às Leis de Incentivo à Cultura (Salicnet).

\section{CULTURA E HEGEMONIA}

A partir de uma abordagem materialista dialética, identifica-se a cultura nas suas principais relações, principalmente acerca das dimensões estéticas, ético-políticas e econômicas. Nesse sentido, tanto um grupo de capoeira angolana quanto um show de axé no carnaval de Salvador apresentam essas dimensões. Em outras palavras, toda cultura materializada num símbolo estético tem um componente ético-político relativo ao trabalho e à identidade dos sujeitos, e que a partir de sua difusão e fruição - comercial ou não - pode gerar diferentes níveis de excedentes, inclusive e principalmente financeiros.

Nessa perspectiva, uma partida de futebol pode se dar ao largo de interesses corporativos, num campo de várzea, protagonizada entre amigos da comunidade e com regras definidas no momento da peleja; ou pode ser organizada dentro de regras bastante rígidas, suportada pela lógica do mercado com as grandes corporações atuando como patrocinadoras e protagonistas do espetáculo. Da mesma forma o samba, que pode ser executado numa roda de amigos numa esquina qualquer da comunidade, com instrumentos improvisados e músicas definidas ali na hora; ou ser extremamente elaborado por uma escola de samba para 0 desfile nas grandes avenidas do samba no Rio ou São Paulo, patrocinado pelas grandes corporações e exibido em tempo real pela TV para todo o globo.

Existe, portanto, uma constante tensão entre espontaneidade e regramento, entre ser protagonista e ser coadjuvante, entre uma cultura de economia e uma economia da cultura, em que as manifestações culturais dependem de recursos financeiros para existir - existência essa que se dá, obviamente, nos marcos da racionalidade do mercado. Essa dinâmica está na gênese da produção e difusão cultural, colocando na maioria das vezes em lados opostos o mercado, com sua racionalidade do lucro, que busca estéticas hegemônicas, e grande parte da produção cultural em si, muitas vezes preocupada com os aspectos ético-políticos de suas manifestações em detrimento da busca do aporte de recursos financeiros para sua sustentabilidade.

No debate sobre cultura, uma noção fundamental é a de hegemonia, nos termos em que foi formulada por Antonio Gramsci. Para o pensador sardo, que escreve a partir da mudança do capitalismo concorrencial para 0 capitalismo monopolista do final do século XIX e início do século $X X$, a hegemonia das classes dominantes passaria a se dar a partir das ideias consensuais e do aumento da participação dos indivíduos na vida social. Nesse sentido, mais do que pela coerção exercida pelo monopólio da força do Estado (ou sociedade política), a hegemonia se daria pelo consenso exercido pelos aparelhos privados de hegemonia. $O$ polo ativo da hegemonia seria então a sociedade civil, entendida como momento superestrutural (e assim determinada em última instância pelas relações objetivas de produção do momento estrutural) e composta pela diversidade, em si contraditória, das organizações privadas que atuam na difusão e consolidação das ideias e valores da sociedade.

Nota-se, assim, uma relação intrínseca entre hegemonia e cultura, entre as ideias, valores e modos de ver e viver o mundo dominantes em uma determinada época, e a cultura que as produz, edita, difunde e possibilita sua fruição. Para Chaui (1983, p. 20, grifos nossos),

[...] hegemonia seria sinônimo de cultura em sentido amplo e sobretudo de cultura em sociedade de classes [...] determina o modo como os sujeitos sociais se representam a si mesmos e uns aos outros, o modo como interpretam os acontecimentos, o espaço, o tempo, o trabalho, o 
lazer, a dominação e a liberdade, o possível e o impossivel, o necessário e 0 contingente, as instituições sociais e políticas, a cultura em sentido restrito, numa experiência vivida ou mesmo refletida, global e englobante, cujas balizas invisíveis são fincadas no solo histórico pela classe dominante de uma sociedade.

Entretanto, como momento superestrutural, a sociedade civil reflete também os interesses contraditórios que se manifestam nas relações objetivas de produção. Nas palavras de Gruppi (1978, p. 70), a hegemonia seria a

[...] capacidade de unificar através da ideologia e de conservar unido um bloco social que não é homogêneo, mas sim marcado por profundas contradições de classe.

A capacidade de unificar ainda que temporariamente essas contradições determina a hegemonia de um grupo ou grupos sobre toda a sociedade, e essa capacidade seria tanto mais elevada quanto a habilidade das classes dominantes apresentarem suas ideias como sendo do interesse de toda a sociedade, ou seja, universalizar seus interesses como se fossem comuns a toda a vida social.

Podemos identificar, assim, a intrínseca relação entre hegemonia e o papel das classes dominantes na difusão de suas ideias para as classes subalternas, apontando a subalternidade para além da questão econômica e atingindo diretamente o terreno da intelectualidade, relacionando assim, saber e poder, cultura e política. Nas palavras de Yazbek (2009, p. 27),

[...] historicamente, os subalternizados vêm construindo seus projetos com base em interesses que não são seus, mas que lhe são inculcados como seus. Experienciam a dominação e a aceitam, uma vez que as classes dominantes, para assegurar sua hegemonia ou dominação, criam formas de difundir e reproduzir seus interesses como aspirações legítimas de toda a sociedade.

Para a circulação difusa desses interesses por toda a sociedade, as classes dominantes utilizam-se da intelectualidade e de sua legitimidade frente aos indivíduos. Entretanto, Gramsci amplia completamente a noção de intelectual, distinta da visão reducionista relativa ao saber do latim ou grego. Com essa ampliação, a noção de intelectual passa a abarcar

[...] o dirigente da sociedade, o quadro social. Um cabo do exército, embora analfabeto, segundo Gramsci, é um intelectual, porque dirige os soldados; intelectual é também um chefe das ligas de assalariados agrícolas, ainda que analfabeto, como eram muitos deles na época de Gramsci, porque organiza os trabalhadores, dirige-os e educa-os (GRUPPI, 1987, p. 84).

Dessa forma, os intelectuais desempenhariam um papel fundamental para a direção moral no seio de um determinado bloco histórico, solidificando o material e o ideal, pois têm capacidade de organizar pensamentos particulares, elevando-os à universalidade e colocando-o como forma de condução de vida para a sociedade. Da mesma forma, como essa hegemonia não é constante no tempo, poderiam se abrir brechas, ou crises de hegemonia, em que nas palavras de Gramsci, o velho já morreu, mas o que é novo ainda não tem condições de nascer. Diante disso, tornase fundamental o estudo de políticas culturais que possibilitem não somente enterrar o que é velho, mas principalmente fomentar 0 nascimento de uma nova ordem ético-política na sociedade.

\section{CAPITALISMO FLEXÍVEL E RELEVÂNCIA DAS POLIITICAS CULTURAIS}

A esfera da cultura não pode ser analisada corretamente se não for situada na totalidade do modo de produção capitalista com as singularidades do modo de acumulação flexível - a partir de suas contradições e múltiplas determinações. $\dot{E}$ exatamente a ligação umbilical entre capitalismo e cultura que interessa ao nosso trabalho, num país marcado pela colonização exploratória, latifundiária e escravista, que promoveu, além da maior diáspora da África, o aniquilamento e a aculturação de milhares de indivíduos dos 
povos originários, resultando numa das Nações mais sincréticas e hierarquizadas do planeta.

Para entender a relevância da ligação entre cultura e capitalismo, é necessário mencionar as mudanças ocorridas no modo de acumulação capitalista principalmente a partir da década de 1970, com a crise deflagrada principalmente a partir do choque do petróleo em 1973 e da sobrevalorização do capital, que diminui as taxas de lucratividade, causando 0 sangramento das contas públicas e a diminuição da capacidade estatal de investimento no setor social, causando descontentamento tanto de capitalistas quanto da classe trabalhadora. Colocada equivocadamente como principal causa da crise, a política social passa a receber cada vez menos investimentos, e logo toda a configuração da proteção social que havia sido exitosa para a reprodução capitalista dos anos anteriores é colocada em cheque, modificando radicalmente a ideologia que suportava 0 Estado de Bem-Estar. Nesse momento, o ideário neoliberal entra em cena demonizando a intervenção do Estado, que deveria ser cada vez menos atuante (e cuja falácia ficou explícita nos episódios das crises financeiras de 2008, em que a atuação do Estado salvou, ainda que até a próxima crise, a atuação de grandes conglomerados empresariais), deixando que as supostas virtudes do livre mercado coordenassem a vida social, inclusive no oferecimento da proteção social.

A palavra de ordem era flexibilidade. A competição acirrada entre as grandes empresas leva a uma luta pela sobrevivência no mercado, provocando a migração de plantas industriais inteiras para localidades com menores custos de reprodução da mão de obra, que deveria ser abundante, pouco qualificada e não sindicalizada, o que acarretou uma forte desterritorialização da produção. Atuando em parceria com as elites de países subdesenvolvidos que assumem a produção das mercadorias, as grandes corporações preocupam-se cada vez menos com a produção e voltam suas atenções para 0 gerenciamento de suas marcas. Em outras palavras, promove-se cada vez mais a diminuição do valor de uso das mercadorias, ao mesmo tempo em que se hipertrofia seu valor de troca. Para Harvey (1992, p. 160), a acumulação flexível
[...] foi acompanhada na ponta de consumo, portanto, por uma atenção muito maior às modas fugazes, e pela mobilização de todos os artifícios de indução de necessidades e transformação cultural que isso implica. A estética relativamente estável do modernismo fordista cedeu lugar a todo o fermento, instabilidade e qualidades fugidias de uma estética pós-moderna que celebra a diferença, a efemeridade, 0 espetáculo, a moda e a mercadificação de formas culturais.

Nesse sentido, ocorre a necessidade premente de utilização de valores transcendentais, das mais diversas e variadas manifestações culturais, ligados às marcas das grandes corporações, processo conhecido por branding na linguagem de negócios. Mais do que uma hiperexploração das manifestações culturais em si, o branding que se implementa na década de 1990 é uma tentativa de tomada radical dos espaços públicos. Naomi Klein (2002) pretende diferenciar a nova fase do branding com relação à publicidade e patrocínios tradicionais, com acordos para 0 uso da imagem em busca da conjunção entre produtos e experiências culturais e sociais positivas. No caso do paradigma do branding proposto pela autora a essência foi

[...] retirar essas associações do reino da representação e transformá-las em uma realidade de vida, em que 0 objetivo não é apenas ter atores mirins bebendo Coca-Cola em comerciais de TV, mas que os estudantes debatam conceitos para a próxima campanha publicitária da Coca-Cola nas aulas de inglês (KLEIN, 2002, p. 195).

Diante dessas perspectivas identificadas, tanto da determinação econômica sobre a cultura quanto da hierarquização das manifestações, a temática cultural se apresenta indissociavelmente ligada ao direito social dos indivíduos ter garantidas suas formas de produção e reprodução imaterial, trazendo à 
tona a questão da equidade no acesso aos bens culturais e aos seus processos de produção e difusão. A partir da premissa que 0 Estado não é nem produtor de cultura tampouco instrumento para seu consumo, uma forma de intervenção democrática deve pautarse por assegurar o direito de criar as obras, isto é, de produzi-las; o direito de acesso às obras culturais produzidas, particularmente 0 direito de fruí-las; e o direito de participar das decisões sobre políticas culturais em que sejam tratados como meros beneficiários (CHAUI, 2006).

Com a globalização, a política cultural passou a se inscrever num conjunto mais amplo de demandas e formas de luta e pertença simbólica, veiculando pretensões de reconhecimento étnico, cultural, sexual, afetivo e de potencialidades criativas inscritas em redes locais específicas de organização e diferenciação social e individual (VENTURA, 2005). Por intermédio de movimentos baseados na solidariedade, muitos de modo ainda informal, passaram a canalizar aspirações das manifestações culturais locais fossem elas sociais, morais, afetivas, de ressentimento, enfim, fontes de motivação de interpelação e resistência política. Atuando como espaço ampliado dos ambientes políticos tradicionais, fomenta a ação de agentes locais que articulam e tematizam repertórios culturais, lógicas e códigos de conduta que não coincidem com os do Estado nem com os do mercado.

Ao tratar não apenas dos direitos de produção simbólica dos bens, mas de um processo generativo, que não pode ser assegurado por leis, mas sim nas práticas operativas que operam fora do Estado e das intervenções discursivas que lutam pelo seu controle, uma política cultural não pode ignorar as bases normativas que sustentam a vida democrática na era pós-industrial (VENTURA, 2005), e para ser efetivamente redistributiva deve consolidar um argumento político em prol das classes marginalizadas, de tal sorte que as políticas culturais são determinantes no sentido de conduzir a hegemonia desses grupos e suas tradições silenciadas pela modernidade eurocêntrica (VENTURA, 2005).

\section{LEIS DE INCENTIVO BASEADAS EM RENÚNCIA FISCAL}

As políticas culturais no Brasil, principalmente a partir da década de 1990, passaram a refletir 0 ideário neoliberal colocado em voga pelo grande capital. 0 Estado mínimo, a focalização, a privatização e a desregulação dos mercados eram palavras de ordem, e na temática da cultura isso não foi diferente. Em 1991, o secretário Sérgio Paulo Rouanet apresentou uma nova lei de incentivos fiscais à cultura, que ficaria conhecida como Lei Rouanet, em que grandes empresas eram estimuladas a patrocinar a área cultural com base na renúncia fiscal por parte do Estado.

O mecanismo, que ficou conhecido como mecenato, é integrante do Programa Nacional de Apoio à Cultura - PRONAC (Lei n 8.313, de 23 de dezembro de 1991). De acordo com o regramento jurídico, no caso 0 Decreto $n^{0}$ 3.000 , de 26 de março de 1999, que trata da cobrança e fiscalização do Imposto sobre a Renda e Proventos de Qualquer Natureza (Regulamento do Imposto de Renda (RIR)/99), as empresas podem abater valores de até $4 \%$ do imposto de renda devido:

Art. 475. A pessoa jurídica tributada com base no lucro real poderá deduzir do imposto devido as contribuições efetivamente realizadas no período de apuração em favor de projetos culturais devidamente aprovados, na forma da regulamentação do Programa Nacional de Apoio à Cultura PRONAC (BRASIL, 1991, art. 26).

$\S 2{ }^{\circ} \mathrm{A}$ dedução não poderá exceder a quatro por cento do imposto devido, observado o disposto no art. 543 (Lei $n^{0} 8.313$, de 1991, art. $26, \S 2^{\circ}$, e Lei $\mathrm{n}^{0}$ 9.532, de 1997, art. $5^{\circ}$ ) (BRASIL, 1999).

Ao longo de duas décadas de funcionamento, o mecanismo tem sido criticado por diversas perspectivas. A principal delas é que tem sido usado prioritariamente para 0 chamado marketing cultural das grandes empresas, inclusive estatais (que coincide com 0 processo de branding problematizado anteriormente), colocando muitas vezes como 
coadjuvante as manifestações culturais em si e desvirtuando o princípio de funcionamento do mecanismo. Uma vez que o mecanismo não exige nenhuma contrapartida, e os projetos aprovados podem captar recursos com qualquer empresa disposta a financiá-los, não existe nenhuma forma de controle democrático sobre estes recursos, que se localizam fora do Orçamento Fiscal da cultura.

Do lado do acesso dos produtores culturais ao mecanismo, exatamente aqueles que realmente fazem da cultura seu dia a dia, a política foi descaracterizada: ao invés de produtores culturais buscarem empresas para captação, os departamentos de marketing é que buscam produtores e agências de propaganda para identificar e editar manifestações que possam ser ligadas às suas marcas. Do lado do acesso do público em geral, muitas vezes se paga muito caro para assistir a uma obra que foi financiada com recursos públicos renunciados pelo Estado, permitindo assim que as empresas possam também auferir lucros financeiros, além, é claro, do ganho institucional para a imagem da marca.

Ainda com relação ao desvirtuamento do mecanismo, existe a possibilidade de 0 incentivador reaver $100 \%$ dos recursos investidos, devido à possibilidade de abatimento de $100 \%$ das despesas operacionais, de acordo com 0 mesmo regramento:

$\S 4^{0}$ Sem prejuízo da dedução do imposto devido nos limites deste artigo, a pessoa jurídica tributada com base no lucro real poderá deduzir integralmente, como despesa operacional, o valor das mencionadas doações e patrocínios (Lei $n^{0} 8.313$, de 1991, art. 26, $\S 1^{\circ}$, e Lei n $n^{0} .249$, de 1995, art. 13, § $2^{\circ}$, inciso I) (BRASIL, 1999).

Nesses casos, 0 incentivador pode abater como despesa operacional todos os gastos com 0 incentivo, diminuindo sua base de lucro a ser tributado e consequentemente 0 valor do imposto devido. Somado ao limite de $4 \%$ de abatimento do imposto de renda, e principalmente com a possibilidade de receitas com a cobrança de valores na bilheteria dos espetáculos, o mecanismo possibilita inclusive a lucratividade pela diferença entre os gastos e estas receitas, ao lado do inquestionável aumento do valor institucional, tudo com a utilização do fundo público.

Outra questão criticada é que 0 mecanismo não conseguiu ainda aumentar 0 valor investido pelo setor privado, funcionando como um dreno de recursos públicos para a publicidade das grandes empresas. Dados do Ministério da Cultura de 2010 indicam que

[...] por meio de renúncia fiscal, foram disponibilizados sem critério $\mathrm{R} \$ 8$ bilhões em 18 anos, sendo $\mathrm{R} \$ 7,2$ bilhões dinheiro do contribuinte. A cada $\mathrm{R} \$ 10$ investidos, $\mathrm{R} \$ 9$ são públicos e apenas $R \$ 1$ é dinheiro do patrocinador privado. Sendo que deste $R \$ 1$ real, mais da metade é aplicado por empresas públicas (BRASIL, 2012, p. 6).

Pode-se identificar ainda que 0 mecanismo funciona contra a equidade, tratando sujeitos desiguais como iguais. Não se pode esperar que um grupo de hip-hop tenha as mesmas capacidades organizativas para submeter um projeto cultural que um grande produtor de uma banda de axé. Além disso, pode-se questionar ainda se um grande banco e uma trupe conceituada como o Cirque de Soleil realmente precisam de recursos públicos para financiamento. Nesse sentido, ao tratar grandes artistas consagrados da mesma maneira que outros com menos destaque e capacidade organizativa e de captação, 0 mecanismo trata desiguais como iguais e vai contra o princípio da equidade. A concentração dos recursos nas regiões mais ricas também é um grave problema do mecanismo, como pode ser observado no Gráfico 1: 


\section{Gráfico 1 - Evolução dos Valores Captados por Região (2004-2013)}

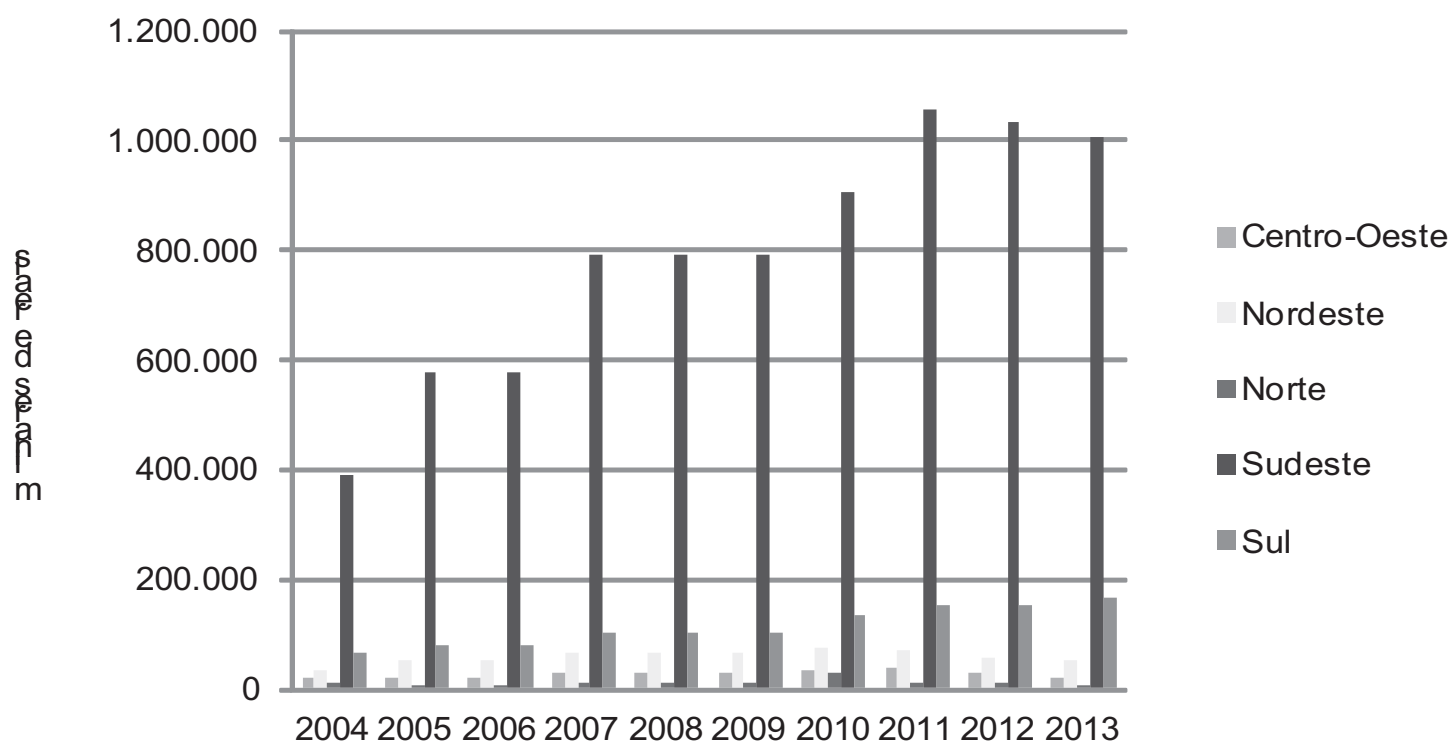

Fonte: Elaboração própria, a partir de dados extraídos de SalicNet/Minc.

Regiões com maior riqueza material efetiva acabam refletindo essas determinações também na alocação de recursos na área cultural, promovendo a reprodução e a agudização das desigualdades regionais. Para efeitos de comparação, para a região Norte, de acordo com o IBGE, o valor do Produto Interno Bruto (PIB) em 2010 foi de $R \$ 201,5$ bilhões e para a região Sudeste foi de $R \$ 2,088$ trilhões, um valor aproximadamente 10 vezes maior. Com relação à captação de recursos, o Norte respondeu por $\mathrm{R} \$ 26,8$ milhões e o Sudeste por $\mathrm{R} \$ 902,3$ milhões (sendo $\mathrm{R} \$ 726,5$ milhões, ou $62 \%$ do total nacional, captados por São Paulo e Rio de Janeiro), um valor 34 vezes maior que a região Norte. Além de manter a desigualdade regional, 0 mecanismo ainda a agudiza, sendo, portanto, frontalmente contra a Constituição Federal de 1988, na medida em que a concentração de recursos captados no Sudeste, principalmente no eixo Rio-São Paulo, reproduz desigualdades econômicas entre as regiões, na direção contrária aos objetivos fundamentais da República: "Art. $3^{0}$ : [...] III erradicar a pobreza e a marginalização e reduzir as desigualdades sociais e regionais." (BRASIL, 1988). Os valores médios dos projetos captados no Sudeste também são bastante superiores aos das outras regiões, como pode ser verificado no Gráfico 2.

Na região Norte, no ano de 2010, há uma forte discrepância dos valores médios captados, referentes a dois projetos vultosos que fizeram aumentar drasticamente a média da região: Estação Conhecimento de Curionópolis - Obras Físicas e Equipamentos de Artes Cênicas e Outros, com valor de captação de R\$ 6.821.719,80; e Estação Conhecimento de Marabá, para os mesmos itens, no valor de $R \$ 8.158 .695,25$, ambos incentivados pela Fundação Vale do Rio Doce para beneficiar comunidades de suas áreas de extração de minérios. 


\section{Gráfico 2 - Evolução do Valor Médio por Projeto Captado (R\$)}

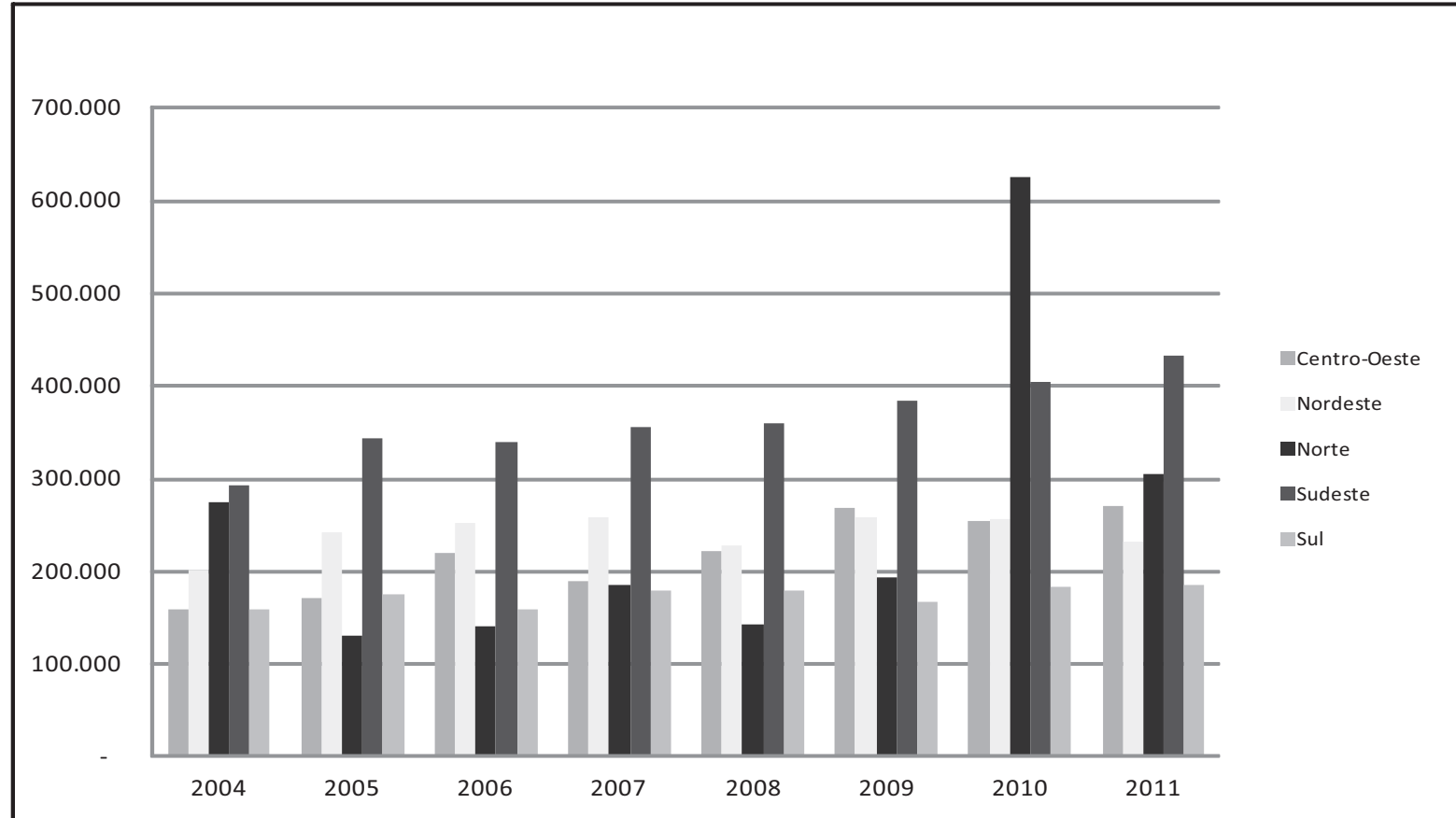

Fonte: Elaboração própria, a partir de dados extraídos de SalicNet/Minc.

Os dados apontam ainda a extrema concentração do mecanismo também com relação à quantidade de projetos captados em cada região, como pode ser visualizado no Gráfico 3.

\section{Gráfico 3 - Evolução da Quantidade de Projetos Captados por Região}

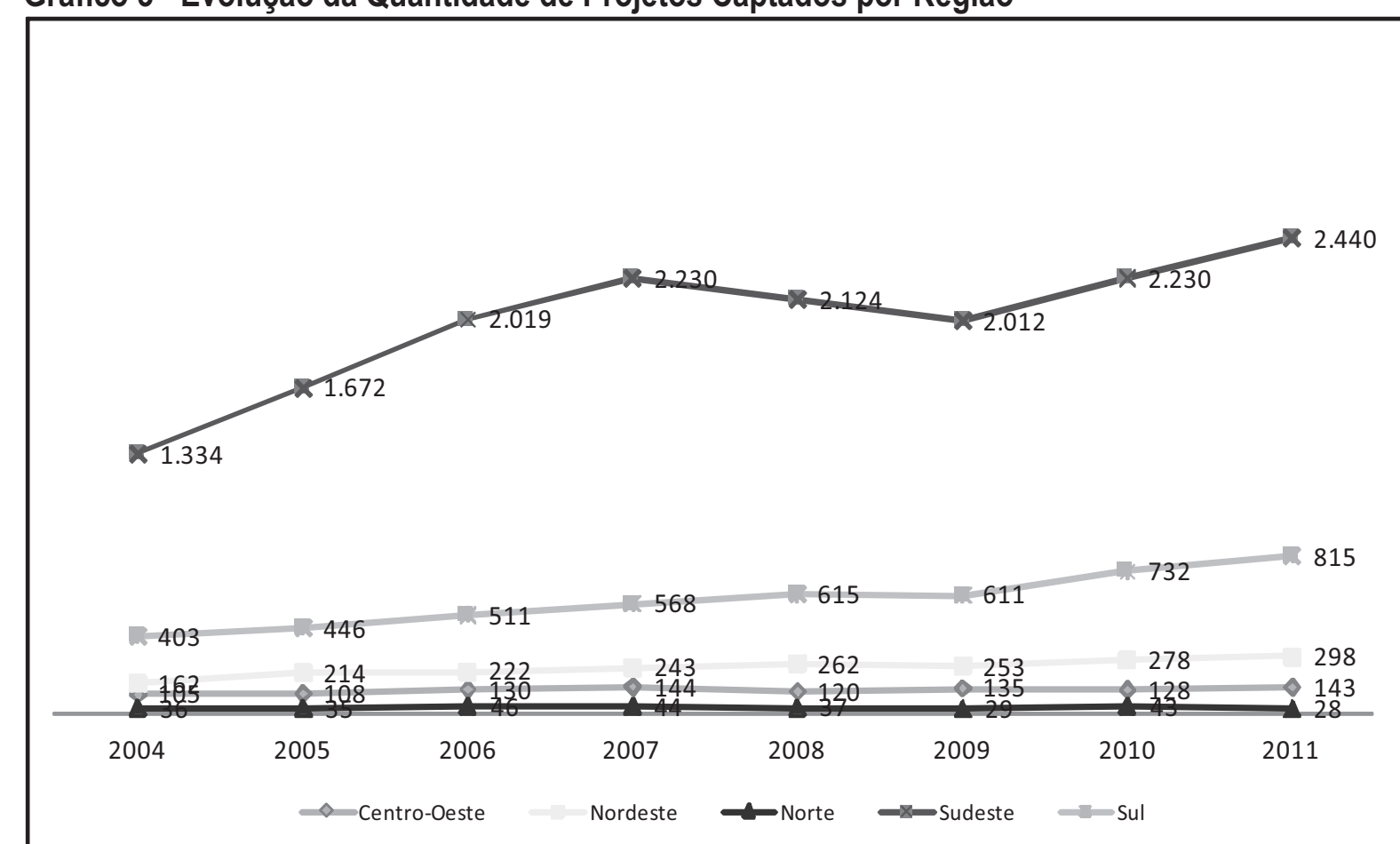

Fonte: Elaboração própria, a partir de dados extraídos de SalicNet/MinC.

Em comparação com a população de demonstram que a população da região cada região, dados do Censo 2010 Sudeste era de 80.353.724 e a da região Norte 
era de 15.865.678, resultando numa relação de aproximadamente cinco vezes; já no tocante ao número de projetos captados, em 2010 o Sudeste captou 2.230 projetos e o Norte 43 , conforme o gráfico abaixo. Isso indica uma relação de aproximadamente $\mathbf{5 2}$ vezes, demonstrando a abissal diferença acerca do acesso ao mecanismo nas diferentes regiões pelos produtores culturais

\section{PROGRAMA CULTURA VIVA}

O Programa Arte, Cultura e Cidadania Cultura Viva - pareceu iniciar uma importante mudança na lógica prevalente do tratamento da cultura meramente como bom negócio, procurando estabelecer um maior equilíbrio entre as dimensões estéticas, ético-políticas e econômicas. Iniciado em 2004 tem como objetivo

\begin{abstract}
[...] reconhecer e potencializar iniciativas culturais de base comunitária, existentes no país, contribuindo para o fortalecimento de uma rede de criação, formação, gestão, registro, pesquisa, intercâmbio, circulação, acesso a bens e serviços culturais $e$, sobretudo, de participação social (INSTITUTO DE PESQUISA ECONÔMICA APLICADA, 2012, p. 3).
\end{abstract}

Baseado em recursos orçamentários, com destinação específica, o Programa possibilita tanto o controle democrático pela sociedade quanto maior poder de manobra do poder executivo na destinação dos recursos. Sua principal ação são os Pontos de Cultura, buscando identificar e reconhecer organizações da sociedade civil que já atuem na temática cultural em seus territórios, a partir de editais públicos. Com esse reconhecimento, as organizações assinam um convênio com 0 Estado e passam a receber o valor de $\mathrm{R} \$ 180$ mil, para o período de dois anos, divididos em cinco parcelas para o financiamento direto de suas atividades. Existe bastante liberdade para a utilização de recursos, sendo a única exigência a utilização de parte da primeira parcela para compra de kit digital com canais de áudio e vídeo. Além dos Pontos, existem também os Pontões de Cultura, espaços maiores e que são responsáveis pela articulação do adensamento de Pontos de Cultura em determinada região. Nesse caso, 0 valor de repasse pode chegar a $\mathrm{R} \$ 500$ mil e 0 prazo do convênio é de três anos.

A ideia do Programa é ativar (numa forma de do in antropológico, nas palavras do então Ministro Gilberto Gil) tipos de manifestações culturais que não se enquadrem na racionalidade do mercado, mas que tenham relações orgânicas com 0 território e a comunidade. A partir do que já existe - e da premissa fundamental que todos têm e são cultura - o programa busca fomentar e promover a sustentabilidade a partir da gestão compartilhada da política cultural entre sociedade e Estado, com ênfase nos aspectos de autonomia, empoderamento, protagonismo e sustentabilidade.

O Programa apresenta uma forma inovadora de relacionamento entre Estado e sociedade no âmbito das políticas culturais, corroborando para uma maior aproximação entre os aspectos estéticos, ético-políticos e econômicos. Ao invés de uma política centralizada e determinada pelo Estado, a preocupação do programa foi entender desde 0 início a sociedade como fazedora de cultura, tratando-se, portanto, de uma área que não pode ficar nem à mercê das preferências estéticas do mercado tampouco às ameaças paralisantes da burocracia estatal.

Uma das inovações mais relevantes do Programa diz respeito à forma de alocação dos recursos na temática cultural. Nas palavras de Celio Turino (2010, p. 23), principal formulador da política,

[...] no lugar de impor uma programação cultural ou chamar os grupos culturais para dizerem o que querem (ou necessitam), perguntamos como querem. Em vez de entender a cultura como produto, ela é reconhecida como processo.

O foco do Programa passa então do paradigma do equipamento cultural para a valorização da diversidade das manifestações, com sua capacidade de criação e potência. A valorização dessas relações tem como premissa a organicidade que as liga ao território, de ser parte inerente da dinâmica 
social local e regional, muitas vezes para além do mero espetáculo, mas como símbolo da valorização da própria dinâmica comunitária.

De forma inédita, o Estado fomenta a articulação da sociedade e tenta se abrir, ainda que de forma bastante lenta, para as demandas de grupos marginalizados historicamente. Essa premissa foi basilar para a seleção das organizações desde os primeiros editais do Programa. Com a segurança possibilitada pela continuidade dos repasses, 0 Programa atua de forma decisiva na sustentabilidade das organizações que não encontram respaldo no financiamento privado. Em 2005, o edital explicitava a necessidade de contemplar públicos e critérios diferenciados de outros editais:

4.2 $\mathrm{Na}$ avaliação dos projetos, a Comissão levará em conta propostas que comprovadamente atendam, ao menos, um dos seguintes públicos: a) estudantes da rede pública de ensino; b) adolescentes e jovens adultos em situação de vulnerabilidade social; c) populações de baixa renda, habitando áreas com precária oferta de serviços públicos e de cultura, tanto nos grandes centros urbanos, como nos pequenos municípios; d) habitantes de regiões e municípios com grande relevância para a preservação do patrimônio histórico, cultural e ambiental; e) habitantes de comunidades indígenas, quilombolas e rurais; f) portadores de deficiência; g) gays, lésbicas, transgêneros e bissexuais GLTB (BRASIL, 2005, p. 8, grifo do autor).

De acordo com o Ministério da Cultura, em 2004 o Programa contava com 70 Pontos e passou a aproximadamente 3.900 Pontos e Pontões de Cultura em 2012, dentre convênios com a União, os estados, municípios e redes de municípios. Assim, o Programa serviu também como um articulador de redes de cultura (temáticas, geracionais, étnicas, locais, regionais) que passaram a se relacionar de forma mais intensa e aprofundada, com todos os benefícios desse intercâmbio cultural. Apesar de ainda não se configurar como direito previsto em lei, já existe o Projeto de Lei 757/2011, em trâmite na Câmara dos
Deputados, visando garantir a perenidade do Programa.

Essa ampliação na quantidade de Pontos e Pontões somente foi possível porque o Programa passou por um efetivo processo de descentralização, com o repasse de recursos financeiros federais para a criação de redes de estados, municípios e redes intermunicipais, além de Pontos específicos para a população indígena, como pode ser observado no Gráfico 4.

Com relação à evolução dos recursos do Programa, o Gráfico 5 mostra uma elevação substancial nos anos de 2008 e 2009, com queda em 2010 e uma pequena retomada em 2011. Já quando comparada com a evolução dos recursos do mecenato, observa-se que, além dos valores absolutos serem bem maiores, a tendência de crescimento do mecenato é bem mais acentuada, indicando a hegemonia do mecanismo no financiamento da cultura.

Por fim, 0 Gráfico 6 apresenta especificamente 0 ano de 2010, identificando que o Programa é mais eficaz que o mecenato em termos de democratização do acesso aos recursos públicos. Apesar de ainda apresentar maior concentração de recursos no Sudeste, observa-se que todas as outras regiões tiveram melhorias na distribuição dos recursos.

\section{CONCLUSÃO}

A análise em tela identificou as enormes diferenças entre as formas de disponibilização de recursos pelas políticas culturais no país. No caso dos gastos tributários, identificados pelas leis de incentivo baseadas na renúncia fiscal, 0 mecanismo apresenta uma série de características que impedem a democratização do acesso e que promovem a manutenção das desigualdades regionais, indo de encontro às premissas da Constituição Federal. Para além da manutenção das desigualdades, foi mostrado que em determinados casos ocorre sua agudização. Assim, toda a sociedade fica 
Gráfico 4 - Total de Pontos e Pontões por Tipo (2011)

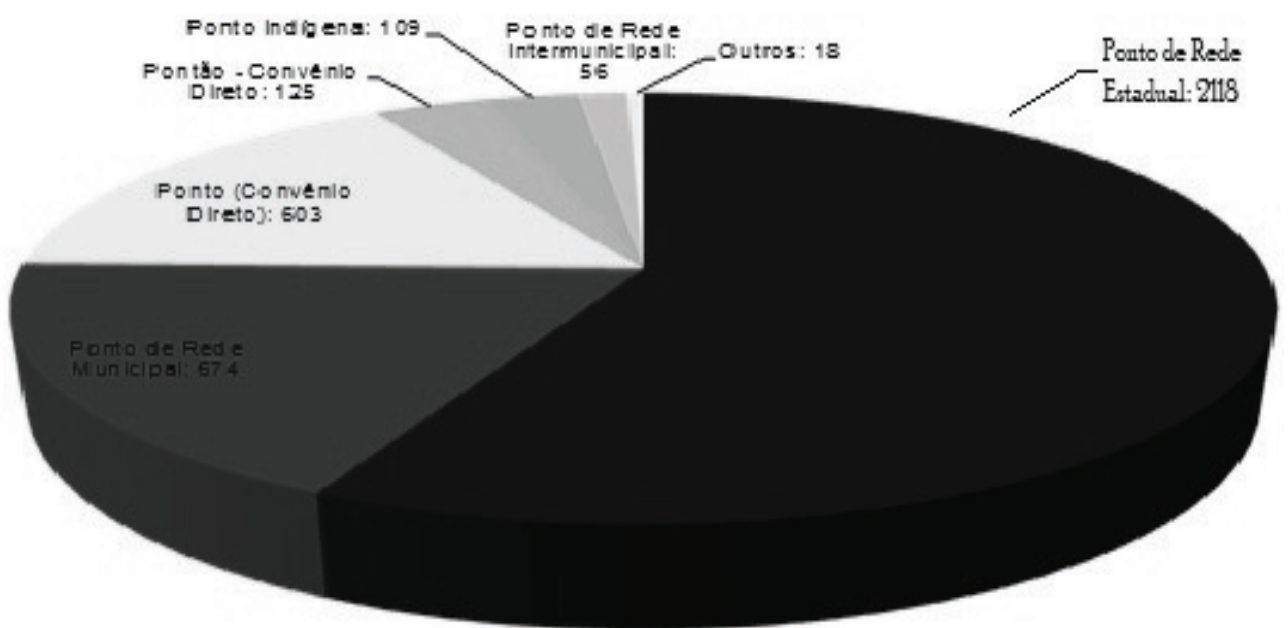

Fonte: Adaptação própria, a partir do Ministério da Cultura (BRASIL, 2012).

Gráfico 5 - Comparativo da Evolução de Recursos 2004 - 2012: Mecenato e Programa Cultura Viva

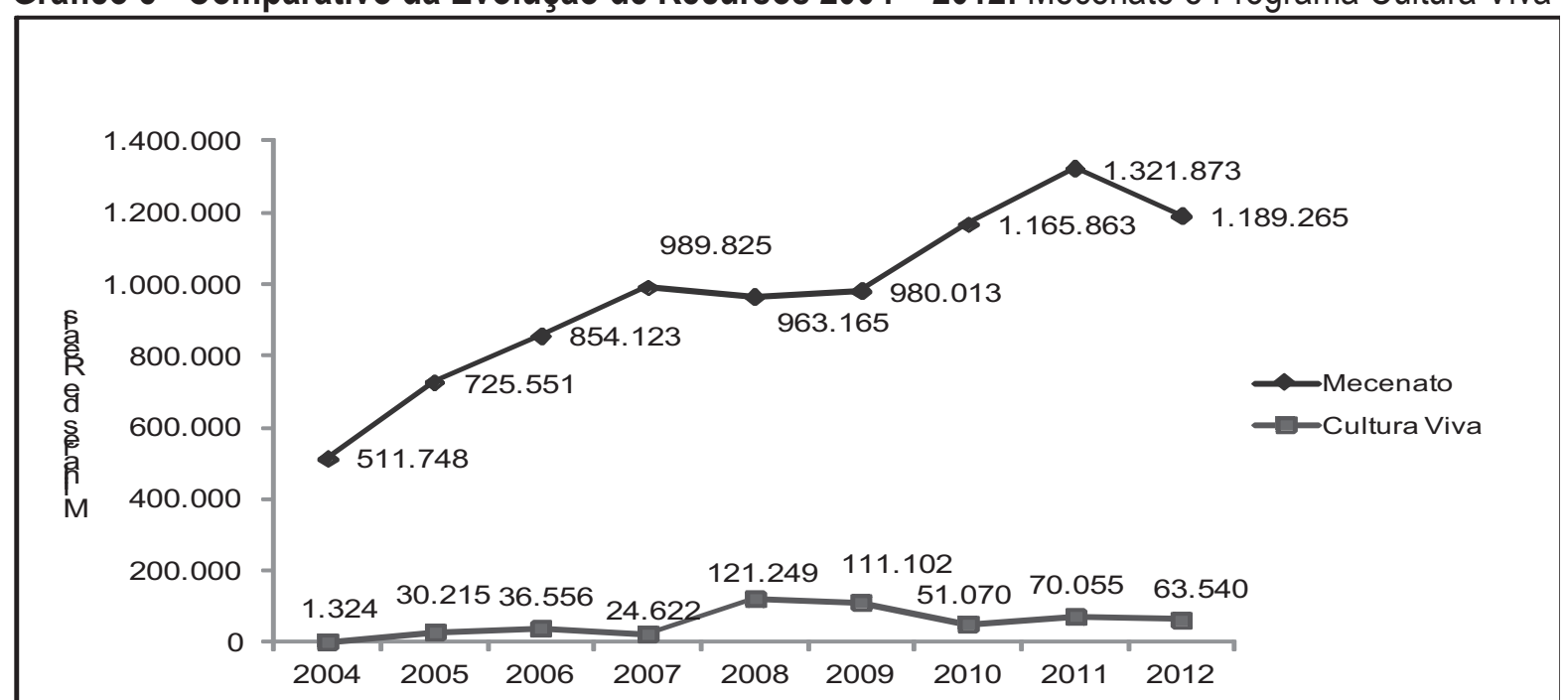

Fonte: Elaboração própria, a partir do Ministério da Cultura (BRASIL, 2012).

\section{Gráfico 6 - Comparativo da Proporção de Recursos por Programa e por Região - 2010}

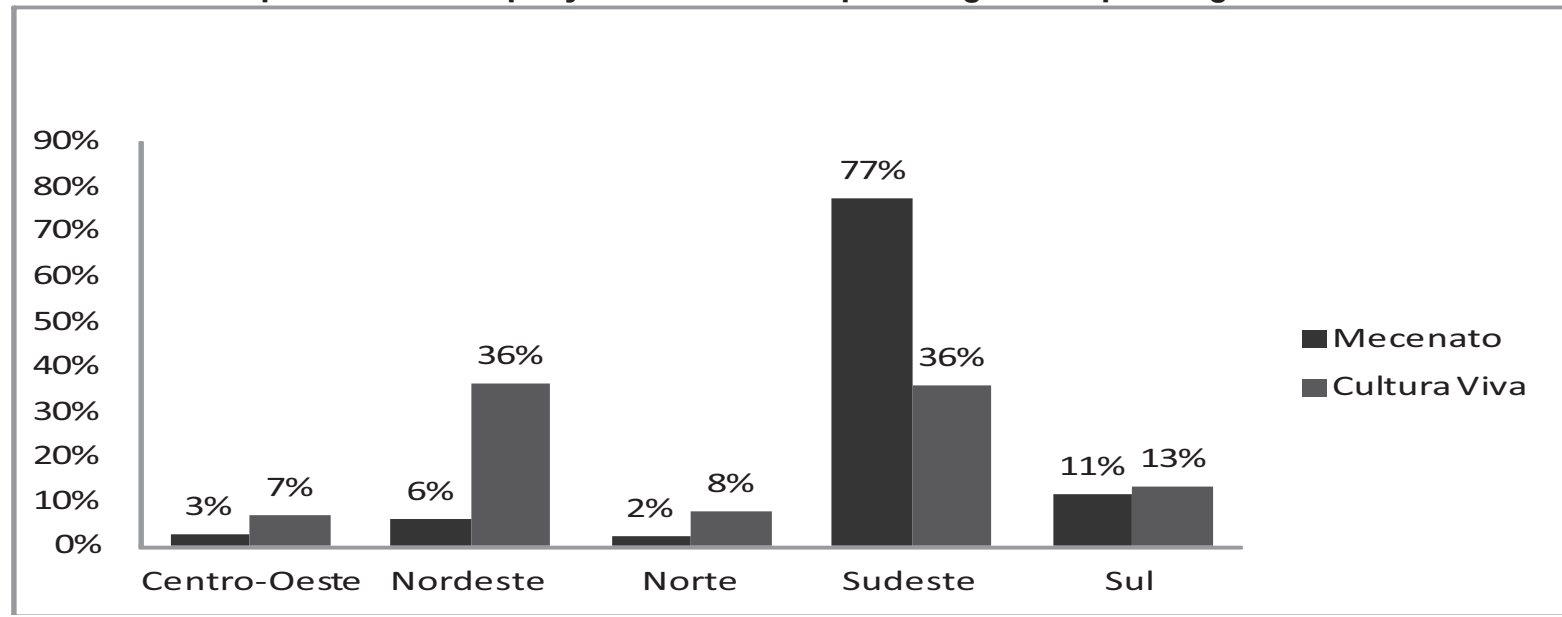

Fonte: Elaboração própria, a partir do Ministério da Cultura (BRASIL, 2012) e dados extraídos do SalicNet/MinC. 
prejudicada, pois as culturas hegemônicas quase sempre estão relacionadas aos interesses e formas de ver e viver o mundo das classes dominantes. Com 0 mecanismo, pequenos produtores se veem impossibilitados de acesso ao financiamento de suas manifestações culturais, e o público em geral tem para sua fruição apenas conteúdos que estejam em consonância com os interesses do grande capital.

No caso dos recursos orçamentários, representados pelo Programa Cultura Viva, foi demonstrada uma nova forma de intervenção do Estado na temática cultural, privilegiando desde 0 início entidades e grupos historicamente marginalizados, tanto na relação com o Estado quanto com o mercado, por não contemplarem estéticas que sejam aderentes à racionalidade do mercado, baseada primeiramente na acumulação de capital, que pode ser aumentada com a mercadorificação dos conteúdos culturais.

A análise demonstrou uma sensível tendência de desconcentração de recursos do Programa, quando comparado ao volume destacado pelo mecenato para a região Sudeste, notadamente no eixo Rio-São Paulo, promovendo, assim, maior equidade no repasse de recursos públicos e um maior equacionamento entre os aspectos simbólicos, ético-políticos e econômicos que estão na gênese dos processos culturais. Apesar disso, verifica-se a tendência de queda de investimentos no Programa, que, além disso, conta com volumes irrisórios frente aos valores do mecenato, apontando para a manutenção da hegemonia do setor privado na determinação dos conteúdos culturais financiados com recursos públicos.

\section{REFERÊNCIAS}

BRASIL. Ministério da Cultura. SALICNET Sistema de Apoio às Leis de Incentivo à Cultura. Brasília, DF, 2004. Disponível em <http://sistemas.cultura.gov.br/salicnet/Salicnet/ Salicnet.php>. Acesso em 21 de fevereiro de 2014.
Secretaria da Cidadania e

Diversidade Cultural. Cultura Viva em Números. Brasília, DF, 2012. Disponível em:<http://www2.cultura.gov.br/culturaviva/wpcontent/uploads/2012/03/Apresentacao-culturaviva-2012-site.pdf>. Acesso em: 14 abr. 2014.

Secretaria de Programas e Projetos Culturais. Edital de Divulgação no 03, de 20 de abril de 2005. Diário Oficial da União. Brasília, DF, n 75, seção 3, p. 8.20 de março. 2005.

Ministério da Fazenda. Secretaria da Receita Federal. Demonstrativo de Gastos Governamentais Indiretos de Natureza Tributária. Brasília, DF, 2013. Disponível em:<http://www.receita.fazenda.gov.br/publico/ estudotributario/BensTributarios/2013/DGT201 3.pdf> Acesso em: 16 dez. 2013.

Ministério do Planejamento, Orçamento e Gestão. Secretaria de Orçamento Federal. Lei 12.952 de 20 de janeiro de 2014. Estima a receita e fixa a despesa da União para o exercício financeiro de 2014. Brasília, DF, 2014. Anexo IV. Disponível em:<http://www.orcamentofederal.gov.br/orcam entos-anuais/orcamento-

2014/orcamentos_anuais_view?anoOrc=2014> . Acesso em: 14 abr. 2014.

Presidência da República. Decreto $\mathrm{n}^{0}$ 3.000, de 26 de março de 1999. Brasília, DF, 1999. Não paginado. Disponivel em:<http://www.planalto.gov.br/ccivil_03/decret o/d3000.htm>. Acesso em: 28 out. 2013.

Lei $n^{0} 8.313$, de 23 de dezembro de 1991. Restabelece princípios da Lei $n^{\circ} 7.505$, de 2 de julho de 1986, institui o Programa Nacional de Apoio à Cultura (Pronac) e dá outras providências. Diário Oficial da União, Brasília, DF, 1991. Disponível em:<http://www.planalto.gov.br/ccivil_03/leis/L8 313 cons.htm>. Acesso em 04 de outubro de 2013. 
República Federativa do Brasil. Constituição Federal de 1988. Brasília, DF, 1988. Disponível em: <http://www.planalto.gov.br/ccivil_03/constituica o/constituicao.htm>. Acesso em 16 de dezembro de 2013.

CHAUI, Marilena. Cidadania cultural: 0 direito à cultura. 1. ed. São Paulo: Fundação Perseu Abramo, 2006.

Seminários sobre o nacional e 0 popular na cultura. 1. ed. São Paulo: Brasiliense, 1983.

GRUPPI, Luciano. 0 conceito de hegemonia em Gramsci. 1 ed. Rio de Janeiro: Edições Graal, 1978.

HARVEY, David. A condição pós-moderna: uma pesquisa sobre as origens da mudança cultural. São Paulo: Edições Loyola, 1992.

INSTITUTO DE PESQUISA ECONÔMICA APLICADA. Relatório de Redesenho do Programa Cultura Viva. Brasília, DF, nov. 2012. Disponível em:<http://www2.cultura.gov.br/culturaviva/wpcontent/uploads/2013/01//PEA-RESULTADODO-REDESENHO-PCV-19dez-SCDC.pdf>. Acesso em: 13 abr. 2014.

KLEIN, Naomi. Sem logo: a tirania das marcas em planeta vendido. Rio de Janeiro: Record, 2002.

TURINO, Célio. Ponto de cultura: a construção de uma política pública. Cadernos Cenpec, São Paulo, v. 5, n. 7, p. 23-31, 2010.

VENTURA, Tereza. Notas sobre política cultural contemporânea. Revista Rio de Janeiro, Rio de Janeiro, n. 15, p. 77-90, jan./abr., 2005.

YAZBEK, Maria Carmelita. Classes subalternas e assistência social. São Paulo: Cortez, 2009.
NOTAS

1 Segundo a Receita Federal, gastos tributários são "[...] os gastos indiretos do governo realizados por intermédio do sistema tributário, visando atender objetivos econômicos e sociais. São explicitados na norma que referencia o tributo, constituindo-se uma exceção ao sistema tributário de referência, reduzindo a arrecadação potencial e, consequentemente, aumentando a disponibilidade econômica do contribuinte. Têm caráter compensatório, quando 0 governo não atende adequadamente a população dos serviços de sua responsabilidade, ou têm caráter incentivador, quando o governo tem a intenção de desenvolver determinado setor ou região." (BRASIL, 2013, p. 11).

2 Dentro do Órgão 42000 Ministério da Cultura, que executou o valor de $\mathrm{R} \$ 1,964$ bilhão, existem 3 programas relevantes em termos de recursos financeiros: Programa 0089 Previdência de Inativos e Pensionistas da União, com execução de R\$ 122,1 milhões; 2107 Programa de Gestão e Manutenção do Ministério da Cultura, execução de R \$568,8 milhões; e 2027 Cultura: Preservação, Promoção e Acesso, execução de $\mathrm{R} \$ 1,25$ bilhão. Destes, apenas o último Programa 2027 contém os valores realmente executados com áreas finalísticas, a cultura em sua substância. É nesta rubrica que se encontra, por exemplo, o Programa Cultura Viva, outro caso analisado neste estudo (BRASIL, 2014).

\section{Eduardo Gomor dos Santos}

Administrador Público

Doutorando em Política Social na Universidade de Brasília (UnB)

Analista de Planejamento e Orçamento, atuando na Coordenação Geral de Planejamento e Avaliação do Ministério do Desenvolvimento Social e Combate à Fome (MDS)

E-mail: eduardogomor@hotmail.com

Carla Beatriz de Paulo

Cientista Política

Mestranda em Política Social na Universidade de Brasília (UnB)

Analista de Planejamento e Orçamento do Governo Federal na Casa Civil da Presidência da República E-mail: carlab87@gmail.com

Ministério do Desenvolvimento Social e Combate à Fome - MDS

Esplanada dos Ministérios, Bloco C, $5^{\circ}$ andar, Brasília/DF

CEP 70046-900

Casa Civil da Presidência da República

Palácio do Planalto, Praça dos Três Poderes, $4^{\circ}$ andar Brasília/DF

CEP $70150-900$ 